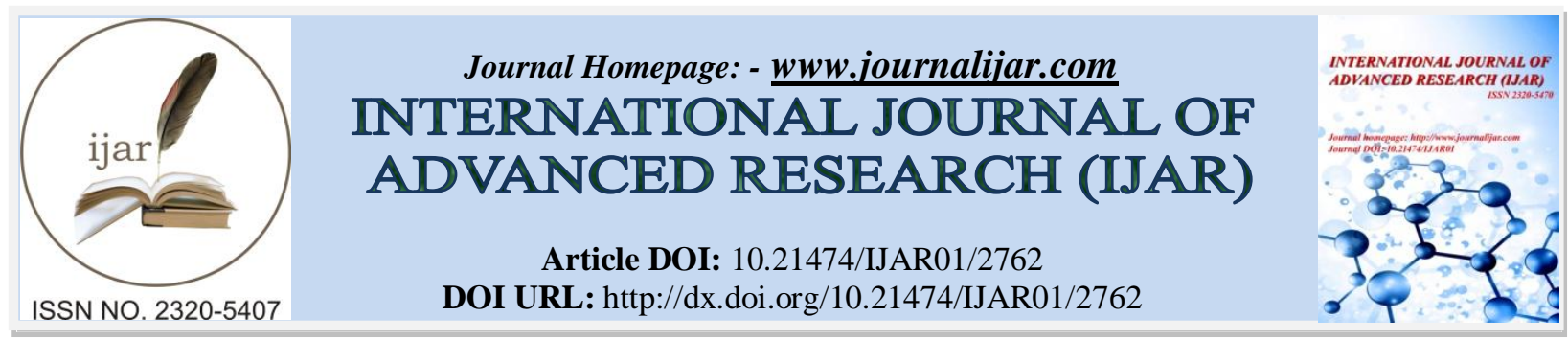

RESEARCH ARTICLE

\title{
EFFECT OF SERUM COPPER LEVELS IN TYPE 2 DIABETES MELLITUS WITH NEPHROPATHY: A CASE CONTROL STUDY IN NORTH INDIAN POPULATION.
}

\section{Sonny Bherwani ${ }^{1}$, ${ }^{*}$ Ashok Kumar Ahirwar ${ }^{2}$, A S Saumya ${ }^{3}$, Sitendu Kumar Patel ${ }^{4}$, A S Sandhya ${ }^{5}$, Brijesh}

Prajapat $^{6}$, Srushtee Bipin Jibhkate ${ }^{7}$, Ritu Singh $^{8}$ and LH Ghotekar'.

Department of Medicine and Biochemistry, Lady Hardinge Medical College and S. S. K Hospital, New Delhi

1. Senior Resident, Department of Accident and Emergency Medicine, Lady Hardinge Medical College (LHMC), New Delhi.

2. Senior Resident, Department of Biochemistry, All India Institute of Medical Sciences (AIIMS), New Delhi. Address of correspondence- - Room no. 3013, Department of Biochemistry, Third Floor, Teaching Block, All India Institute of Medical Sciences (AIIMS), Ansari Nagar, New Delhi-110027.

3. Junior Resident, Department of Pathology, Lady Hardinge Medical College (LHMC), New Delhi.

4. Senior Resident, Department of Gastroenterology, Max Super Specialty Hospital, Saket, New Delhi.

5. Senior Resident, Department of Chest and TB, PGIMS, Rohtak, Haryana.

6. Senior Resident, Department of Pulmonary and Critical care.PGIMS, Rohtak, Haryana.

7. Assistant Professor, Department of Biochemistry, LN Medical College and JK Hospital, Bhopal, MP

8. Professor, Department of Biochemistry, Lady Hardinge Medical College (LHMC), New Delhi.

9. Professor, Department of Medicine, Lady Hardinge Medical College (LHMC), New Delhi.

\section{Manuscript Info}

Manuscript History

Received: 15 November 2016

Final Accepted: 17 December 2016

Published: January 2017

Key words:-

Diabetes Mellitus, Diabetic

Nephropathy, Serum copper.

\section{Abstract}

associated with various complications such as diabetic nephropathy. It is most common cause of End Stage Renal Disease (ESRD) in diabetic individual. In various studies, altered levels of serum copper levels are associated with diabetic complications such as diabetic nephropathy. We studied serum copper levels in type 2 diabetic individual with and without nephropathy.

Materials and Methods- The study population consisted of 100 type 2 diabetic individual which was further divided into two groups, first group consisted of 50 diabetic individual with nephropathy and second group consisted of 50 diabetic individual without nephropathy. Diabetic nephropathy status was assessed by spot urinary albumin creatinine ratio and GFR. Serum copper levels were measured by colorimetric method.

Result- Mean serum copper levels were significantly higher in diabetic patient with nephropathy $(111.8 \pm 13.9 \mathrm{mg} / \mathrm{dl})$ as compare to diabetic patient without nephropathy $(102.3 \pm 16.2 \mathrm{mg} / \mathrm{dl}),(p=0.002)$. Serum copper was also positively correlated with weight of subject $(\mathrm{r}=0.263$, $p=0.009)$, and negatively correlate with serum zinc $(\mathrm{r}=-0.263, p=$ 0.009 ).

Conclusion- Diabetic nephropathy is the leading cause of death in diabetic individual. Our study points toward the increased serum copper levels are associated with diabetic nephropathy. Thus we could use copper chelator in an attempt to decrease serum copper, so that
Introduction-Diabetes mellitus is chronic metabolic disease,
Corresponding Author:- Ashok Kumar Ahirwar.

Address:- Department of Biochemistry, All India Institute of Medical Sciences (AIIMS), New Delhi. 
overall management of diabetic individual.

diabetic nephropathy could be

Copy Right, IJAR, 2016,. All rights reserved. prevented and thus improve

\section{Introduction:-}

Diabetes mellitus is the chronic, lifelong metabolic disease, which is characterised by hyperglycemia and it produce the organ damage by various mechanism such as free radical injury, formation of advanced glycation end products and various toxic metabolite which accumulate during the metabolism of excess of glucose such as polyol intermediate, sorbitol, hexose-amine etc.[1] These abnormalities in the presence of chronic hyperglycemia ultimately lead to various chronic micro and macro vascular complication such as diabetic nephropathy, diabetic retinopathy, diabetic neuropathy and include cardiovascular, cerebrovascular and various peripheral vascular diseases respectively.[2]

The prevalence of diabetes mellitus and associated complication is increasing globally at a faster rate. At present there are approximately 220 millions of diabetic patient present globally as per World Health Organisation (WHO) and if the current growth is not checked, then number of diabetes patient would exceeds 435 million in 2030 , according to International Diabetes Federation (IDF).[3,4] WHO has already declared India as world capital of Diabetes.

Diabetic Nephropathy (DN) is the leading cause of chronic kidney failure all over the world.[5] Clinical hallmark of diabetic nephropathy include elevated blood pressure, elevated urinary proteins and abnormal renal function test.

It is one of the most significant long term complications in terms of morbidity and mortality for diabetic patient which usually present in 40-50\% of diabetic patients out of which $20 \%$ patient progress to End Stage Renal Disease (ESRD).Thus it points toward the certain population of diabetic patient who are susceptible for the development of diabetic nephropathy. The potential modifiable risk factors for the its development and progression are hyperglycemia, hypertension, and other minor risk factors including diabetic factor.[6]

It has been shown in various studies that alterations in levels of various elements lead to development of diabetes mellitus and its associated complications such as diabetic nephropathy. It has been suggested that perturbations in mineral metabolism are more pronounced when metabolic control is poor or if vascular complications are present. It has also been shown that excess of $\mathrm{Cu}$ lead to increase predisposition of vascular disease in diabetic patient.[7]

So we framed the hypothesis that alter levels of copper is the culprit for the development of diabetic nephropathy as the complication of diabetes. There also lack of studies regarding alter levels of copper in North Indian diabetic patient with and without Nephropathy.

\section{Materials And Methods:-}

\section{Study design:-}

This hospital based observational case control study was done for the period of 3 years from 2013 to 2015 in the Department of Medicine with the collaboration of Department of Biochemistry, Lady Hardinge Medical College (LHMC) and Associated Hospitals, New Delhi. Institutional Ethical Committee approved our study design.

\section{Study Population:-}

Our study included 100 diabetic patients who had visited diabetic OPDs and routine OPDs of Department of Medicine, LHMC, New Delhi. Study population was divided into two groups. First group consisted of 50 diabetic patients with nephropathy and second group consisted of 50 diabetic patients without nephropathy.

\section{Inclusion criteria:-}

Known cases of type 2 diabetes mellitus for minimum period of 5 years of duration.

Exclusion criteria:-

Patient not willing to participate in the study, acute and chronic illness excluding diabetes mellitus, patient having hormonal abnormalities, drug intake history which have nephrotoxic effect and deleterious effect on glucose profile of diabetic patient were excluded from the study. 
Bilingual and informed consent was taken from the patient and his relatives. Thorough clinical history and medical examination was done especially related to diabetes and diabetic nephropathy.

\section{Sample collection:-}

Five $\mathrm{ml}$ of venous sample was taken from the subject under sterile condition into plain vials without anticoagulant for routine and special investigations, anticoagulant containing purple cap vials for hemogram and $\mathrm{NaF}$ with anticoagulant containing grey cap vials for blood glucose profile. The plain vials were kept for half an hour for clotting. After clotting, the plain vials were centrifuged at the speed of 2000 RPM for 5 minutes. The serum was separated and aliquot into serum tubes. For routine biochemical investigations serum was sent immediately for analysis. For special investigation the serum was kept at $-20^{\circ} \mathrm{C}$ for batch analysis of serum copper.

For assessing the status of diabetic nephropathy in the study population, we measured spot urine albumin creatinine ration $(\mathrm{U}-\mathrm{A} / \mathrm{C}$ ) and GFR. U-A/C values included Normoalbuminuria: $<30 \mathrm{mg} / \mathrm{g}$ of creatinine, Microalbuminuria: $30-300 \mathrm{mg} / \mathrm{g}$ of creatinine and Macroalbuminuria: $>300 \mathrm{mg} / \mathrm{g}$ of creatinine. Cockroft - Gault equation was used to assess GFR.[8]

Batch analysis was done to measure serum magnesium in the preserved samples by using fully AUTOMATED ANALYSER SYNCHRON BECKMAN CX-9 using standard reagent and kits. All kits were of centronic $\mathrm{GmbH}$, Germany. Serum copper measurement was based on direct colorimetric method without deproteinisation in serum. In a pH 4.7 buffer system, copper is released from its carrier protein, the ceruloplasmin, and forms complexant 3,5-DiBr-PAESA[4-(3,5-dibromo-2-pyridylazo)-N-ethyl-N-(3-sulfopropyl)aniline] a stable complex. The colour intensity of this complex is proportional to the amount of copper in the sample. Lyophilised control serum was used. The colour so formed was red which was measured spectrophotometrically at wavelength of 582 nm. Reagent kit name-Copper REF 17106. Lot number -20299.

The normal values for serum copper was considered as $70-140 \mu \mathrm{g} / \mathrm{dl}$ for male and $80-155 \mu \mathrm{g} / \mathrm{dl}$ for female.[9]

\section{Statistical Analysis:-}

All data are expressed as mean \pm SD. (standard deviation) and statistical analysis was conducted using SPSS statistical package, version 20.0 (SPSS Inc., Chicago, IL, USA). A $p$ value $<0.05$ was considered as significant. The Student's t-test was used to compare the mean between two groups for normally distributed data. Pearson's correlation was used to find out the correlation among the various parameters.

\section{Results:-}

Table 1 showing the renal function of study population which shows that group 1 had diabetic nephropathy as compare to group 2.

Table 2 showing that in group 1, mean serum copper level had significantly higher value than that of group 2 .

On Pearson's correlation, serum copper was positively correlated with weight of subject $(\mathrm{r}=0.263, p=0.009)$, and negatively correlate with serum zinc $(\mathrm{r}=-0.263, p=0.009)$.

Table 1:- Renal profile of study population

\begin{tabular}{|c|c|c|c|c|c|}
\hline & \multicolumn{2}{|c|}{$\begin{array}{l}\text { Diabetic patient } \\
\text { nephropathy }(\mathrm{n}=50)\end{array}$} & \multicolumn{2}{|c|}{$\begin{array}{lrl}\begin{array}{l}\text { Diabetic patient } \\
\text { nephropathy }(\mathrm{n}=50)\end{array} & \\
\end{array}$} & \multirow[t]{2}{*}{$p$ value } \\
\hline Parameters & Mean & SD & Mean & SD & \\
\hline U-A/C (mg/g) & 130.7 & 46.72 & 18.37 & 4.99 & $<0.001^{*}$ \\
\hline GFR (ml/min) & 62.16 & 24.74 & 108.44 & 7.96 & $<0.001^{*}$ \\
\hline
\end{tabular}

${ }^{*} \mathrm{p}$ value $\leq 0.05$ is considered statistically significant.

Table 2:- Serum Copper status of study population

\begin{tabular}{|l|l|l|l|l|l|}
\hline & \multicolumn{2}{|l|}{$\begin{array}{l}\text { Diabetic patient with } \\
\text { nephropathy }(\mathrm{n}=50)\end{array}$} & $\begin{array}{l}\text { Diabetic patient without } \\
\text { nephropathy }(\mathrm{n}=50)\end{array}$ & $p$ value \\
\hline Parameters & Mean & SD & Mean & SD & \\
\hline Serum copper $(\mathrm{mg} / \mathrm{dl})$ & 111.8 & 13.9 & 102.3 & 16.2 & $0.002^{*}$ \\
\hline
\end{tabular}

*p value $\leq 0.05$ is considered statistically significant. $\mathrm{SD}=$ Standard Deviation

\section{Discussion:-}


Diabetes mellitus is a chronic metabolic disorder which affects carbohydrate, lipid and protein metabolism. It has already taken pandemic in terms of number of diabetic patient. It lead to various complications, one of them is diabetic nephropathy which is responsible for chronic kidney failure in diabetic patients. This complication is responsible for high mortality and morbidity of the person suffering from type 2 diabetes mellitus.

There is need of finding the risk factor for development of diabetic nephropathy and its proper management, so that we can prevent the death from renal failure in diabetic individual.

In various studies, it has been seen that there is a strong relation between some specific oligoelements and diabetes mellitus.[10] It has been seen that altered serum copper $(\mathrm{Cu})$ levels are associated with diabetes and associated complications.[11]

Diabetes complications associated with the increased free radical production leading to oxidative damage, and many of the pathological effects of copper overload are consistent with an oxidative damage to membranes or various macromolecules. $\mathrm{Cu}$ is involved in oxidation-reduction reactions and has a dominant role in diverse proteins such as cytochrome oxidase at the terminal end of the mitochondria electron transport chain. This divalent cation is also involved in super oxide dismutase activity. Copper has the capacity to form covalent bounds and it takes part in many redox processes. Copper ions are involved in generation of reactive oxygen species through Fenton reaction, having a pro-oxidant action.[12]

Copper ion is well known for cytotoxic effect due to its redox chemistry. Excess of copper aggravate the hyperglycemia which causes glycation of various protein and also displaces copper from copper binding site of protein and thus further aggravates the hypercuperemia, which lead to more oxidative damage to various tissue and organs.[13]

There are lots of studies done in serum copper levels in diabetic individual with and without complications, but still there is no uniformity in the results levels of copper in these patients. Our study result is in agreement with the study done by Rusu et al [14] and Noto et al [15] in which serum copper levels are increased in diabetic individual with complications such as diabetic nephropathy, but Prabodh et al found no difference of serum copper level in diabetic patient as compare to healthy control.[16] Moreover Hazzim et al showed in his study that serum copper levels are significantly decrease in diabetic patient with complications as compare to diabetic patient without complications.[17]

So our study hints toward the increase serum copper levels in diabetic patients with associated complications. Moreover we can treat the diabetic patient with copper specific chelator, so that various complications of diabetes mellitus including diabetic nephropathy could be prevented as it has been proven beneficial in various animal models.[18,19,20,21,22] Our study could give new insight for understanding the risk factor for development of diabetic nephropathy and also therapeutic modality could be develop to remove excess of copper ions from the diabetic patient, so that overall management of diabetic patient improves by decreasing various complication associated with copper induce oxidative stress.

Strength of our study is well characterised study population and standardized techniques to measures various parameters of the study.

\section{Limitations:-}

Our study had small sample size and study populations were selected from local area. Even it was hospital based case control study, so it would be difficult to predict cause and effect relationship.

\section{Suggestions:-}

Large prospective, interventional studies need to be undertaken to confirm the cause and effect relationship and to assess the protective role of supplementing copper chelator in human for preventing the development and progression of nephropathy.

\section{Conflict of Interest:-}

No conflict of interest to declare. 


\section{Acknowledgements:-}

Special thanks to the Dr Surajeet Kumar Patra, Dr Shilpa Bhardwaj and other staff of the Lady Hardinge Medical College, New Delhi.

\section{References:-}

1. Ceriello A, Motz E. Is oxidative stress the pathogenic mechanism underlying insulin resistance, diabetes, and cardiovascular disease? The common soil hypothesis revisted. Arterioscler Thromb Vasc Biol.2004;24(5):816-23.

2. King GL, Brownlee M. The cellular and molecular mechanisms of diabetic complications. Endocrinol Metab Clin North Am.1996;25(2):255-7.

3. Wild S, Roglic G, Green, Sicree R, King H. Global prevalence of diabetes: estimates for the year 2000 and projections for 2030. Diabetes Care. 2004; 27(5):1047-53.

4. World Healh Organisation. Prevalence of diabetes. In: Diabetes Action now, editor. WHO; 2004.

5. Elina EL, Jerums G, Skene A, Grammer P, Power D, Cheong KY, Panagiotopoulos S, McNeil K, Baker ST, Fioretto $\mathrm{P}$ et al. Renal structure in normalbuminuric and albuminuric patient with type 2 diabetes and impaired renal function. Diabetes Care. 2013.Nov;36(II):3620-6.

6. Murea M, Ma L, Freedman BI. Genetic and environmental factors associated with type 2 diabetes and diabetic vascular complications. The Review of Diabetic Studies : RDS. 2012;9 (1):6-22.

7. Zargar AH, Shah NA, Massodi SR, Laway BA, Dar FA, Khan AR, Sofi FA, Wani AI. Copper, zinc and magnesium levels in non-insulin-dependent diabetes mellitus. Postgrad Med J. 1998(Nov); 74(877): 665-8.

8. Michels WM, Grootendorst DC, Verduijn M, Elliott EG, Dekker FW, Krediet RT. Performance of the CockcroftGault, MDRD, and New CKD-EPI Formulas in Relation to GFR, Age, and Body Size. Clinical Journal of the American Society of Nephrology : CJASN. 2010;5(6):1003-1009

9. Burtis C A, Ashwood E R, Bruns E D. Tietz Textbook of Clinical Chemistry And molecular diagnostic. 1Vth ed: Saunders. Philadelphia. 2008.

10. Mohanty SS, Pinnelli VB, Murgod R, Raghavendra DS. Evaluation of serum copper, magnesium and glycated haemoglobin in type 2 diabetes mellitus. Asian J Pharm Clin Res.2013;6(2):188-190.

11. Viktorinova A, Toserova E, Krizko M, Durackova Z. Altered metabolism of copper, zinc, and magnesium is associated with increased levels of glycated hemoglobin in patients with diabetes mellitus. Metabolism 2009; 58:1477-1482.

12. Bremner I. Manifestation of copper excess. Am J Clin Nutr. 1998; 67(5):1069S-1073S.

13. Quilliot D, Dousset B., Guerci B, Dubois F, Drouin P, Ziegler O. Evidence that diabetes mellitus favors impaired metabolism of zinc, copper, and selenium in chronic pancreatitis. Pancreas 2001; 22: 299-306.

14. Rusu ML, Marunoiu C, Rusu LD, Olivia FMN, Cristina HN, Laura P. Testing of Magnesium, Zinc and Copper Blood Levels in Diabetes Mellitus Patients. Acta Universitatis Cibiniensis.Seria F Chemia. 2005; 8:61-63.

15. Noto R, Alicata R, Sfogliano L, Neri S, Bifarella M. A study of cupremia in a group of elderly diabetics. Acta Diabetol Lat. 1984; 21(1):79-85.

16. Prabodh S, Prakash DS, Sudhakar G, Chowdary NV, Desai V, Shekhar R. Status of copper and magnesium levels in diabetic nephropathy cases: a case-control study from South India. Biological trace element research. 2011;142(1): 29-35.

17. Hazzim H Edan. Serum copper level in non insulin diabetes mellitus, Al-Mustansyriah University .Mustansiriya Med J. 2006; 6(1):36-41.

18. Cooper GC. Selective divalent copper chelation for the treatment of diabetes mellitus. Current Medicinal Chemistry.2012;19(17):2828-2860.

19. Cooper GJ, Chan YK, Dissanayake AM, Leahy FE, Keogh GF, Frampton CM, Gamble GD, Brunton DH, Baker JR, Poppitt SD. Demonstration of a hyperglycemia-driven pathogenic abnormality of copper homeostasis in diabetes and its reversibility by selective chelation: quantitative comparisons between the biology of copper and eight other nutritionally essential elements in normal and diabetic individuals. Diabetes.2005;54(5):1468-1476.

20. Lu J, Gong D, Choong SY, Xu H, Chan YK, Chen X, Fitzpatrick S, Glyn-Jones S, Zhang S, Nakamura T et al. Copper(II)-selective chelation improves function and antioxidant defences in cardiovascular tissues of rats as a model of diabetes: comparisons between triethylenetetramine and three less copper-selective transition-metal-targeted treatments. Diabetologia.2010;53(6):1217-1226.

21. Bakker SJL, Navis G, Gans ROB. Copper chelation as a potential treatment for left-ventricular hypertrophy in type 2 diabetes. Diabetologia.2009;52(10)2244.

22. Cooper GJ, Phillips AR, Choong SY, Leonard BL, Crossman DJ, Brunton DH, Saafi 'L, Dissanayake AM, Cowan BR, Young AA et al. Regeneration of the heart in diabetes by selective copper chelation. Diabetes 2004;53(9) 25012508. 